\title{
Partial Pressure of Carbon Dioxide Measurement
}

National Cancer Institute

\section{Source}

National Cancer Institute. Partial Pressure of Carbon Dioxide Measurement. NCI

Thesaurus. Code C82625.

A measurement of the partial pressure of carbon dioxide in a sample. 